\title{
A systematic review of radiotherapy capacity in low- and middle-income countries
}

\section{Surbhi Grover ${ }^{1 *}$, Melody J. Xu' ${ }^{1}$, Alyssa Yeager ${ }^{1}$, Lori Rosman ${ }^{2}$, Reinou S. Groen ${ }^{3}$, Smita Chackungal $^{4}$, Danielle Rodin ${ }^{5}$, Margaret Mangaali ${ }^{1}$, Sommer Nurkic ${ }^{2}$, Annemarie Fernandes' ${ }^{1}$, Lilie L. Lin', Gillian Thomas ${ }^{5}$ and Ana I. Tergas ${ }^{6}$}

1 Department of Radiation Oncology, Perelman School of Medicine, University of Pennsylvania, Philadelphia, PA, USA

2 Johns Hopkins School of Public Health, Baltimore, MD, USA

${ }^{3}$ Department of Gynecology and Obstetrics, Johns Hopkins Hospital, Baltimore, MD, USA

${ }^{4}$ Department of Surgery, University of Western Ontario, London, ON, Canada

${ }^{5}$ Department of Radiation Oncology, University of Toronto, Toronto, ON, Canada

${ }^{6}$ Department of Obstetrics and Gynecology, Columbia University College of Physicians and Surgeons, New York, NY, USA

\section{Edited by:}

Daniel Grant Petereit, Rapid City

Regional Hospital, USA

Reviewed by:

Tim Williams, Boca Raton Regional Hospital, USA

David Andrew Pistenmaa, University

of Texas Southwestern Medical

Center, USA

*Correspondence:

Surbhi Grover, University of

Pennsylvania, Perelman Center for

Advanced Medicine, Department of

Radiation Oncology, 3400 Civic

Boulevard, Philadelphia, PA

19104-6021, USA

e-mail:surbhigrover@gmail.com
Objectives: The cancer burden in low- and middle-income countries (LMIC) is substantial. The purpose of this study was to identify and describe country and region-specific patterns of radiotherapy (RT) facilities in LMIC.

Methods: A systematic review of the literature was undertaken. A search strategy was developed to include articles on radiation capacity in LMIC from the following databases: PubMed, Embase, CINAHL Plus, Global Health, and the Latin American and Caribbean System on Health Sciences Information. Searches included all literature up to April 2013.

Results: A total of 49 articles were included in the review. Studies reviewed were divided into one of four regions: Africa, Asia, Eastern Europe, and South America. The African continent has the least amount of resources for RT. Furthermore, a wide disparity exists, as $60 \%$ of all machines on the continent are concentrated in Egypt and South Africa while 29 countries in Africa are still lacking any RT resource. A significant heterogeneity also exists across Southeast Asia despite a threefold increase in megavoltage teletherapy machines from 1976 to 1999, which corresponds with a rise in economic status. In LMIC of the Americas, only Uruguay met the International Atomic Energy Agency recommendations of $4 \mathrm{MV} /$ million population, whereas Bolivia and Venezuela had the most radiation oncologists (>1 per 1000 new cancer cases). The main concern with the review of RT resources in Eastern Europe was the lack of data.

Conclusion: There is a dearth of publications on RT therapy infrastructure in LMIC. However, based on limited published data, availability of RT resources reflects the countries' economic status. The challenges to delivering radiation in the discussed regions are multidimensional and include lack of physical resources, lack of human personnel, and lack of data. Furthermore, access to existing RT and affordability of care remains a large problem.

Keywords: radiation capacity, global health, low- and middle-income countries, radiation oncology access, systematic review, systematic review

\section{INTRODUCTION}

As populations' age and infectious disease control extends lifespan, cancer and other non-communicable diseases are becoming increasingly significant burdens of mortality in low- and middleincome countries (LMIC) (1). Over 70\% of cancer cases will be diagnosed in LMIC by 2030 (2). Yet most developing countries do not have the resources or infrastructure to prevent, diagnose, or treat this growing burden of cancer (2). Compounding the issue is the lack of cancer registries and cancer treatment capacity in most of the developing world. Existing data represents only a fraction of the true burden of cancer, with our best estimates being estimates at best.
Leading medical and public health organizations have spearheaded international initiatives to increase awareness of this issue, but great needs still exist (3). One organization, the International Atomic Energy Agency (IAEA), has organized the Directory of Radiotherapy Centres (DIRAC), which acts as a central record and quantification of international radiotherapy (RT) capacity. Apart from DIRAC, few reports exist that describe the capacity requirements necessary to deliver RT. This capacity includes country-specific infrastructure, equipment, personnel training, quality assurance, and challenges surrounding RT facilities. The objective of this study was to perform a systematic review of RT capacity in LMIC as documented in the literature. In addition, we 
aimed to compare reports in the literature to that of reports from the IAEA.

\section{MATERIALS AND METHODS}

We searched PubMed (1946 to April 2013), Embase (1974 to April 2013), CINAHL Plus (1937 to April 2013), Global Health (1910 to April 2013), and the Latin American and Caribbean System on Health Sciences Information (LILACS) (1982 to April 2013). A core strategy was developed in PubMed and then translated for each database. All search strategies were developed using a combination of controlled vocabulary and keyword terms to define the concepts of radiation therapy, health services, and LMIC. Searches were run on April 19, 2013. (See Supplementary Material for more details on search strategies.)

All citations were imported into a reference management system and duplicates were removed. All citations were reviewed by two authors at the title and abstract level for pre-defined inclusion and exclusion criteria as defined below. A third author resolved disagreements between the initial two reviewing authors.

Articles on radiation capacity and facilities in LMIC were included. Articles not including low- or middle-income countries (as determined by the World Bank, see Supplementary Material for complete list) and radiation facilities or capacity were excluded.

Based on the initial database search, abstracts were selected for final review (Figure 1). If they met the above inclusion criteria, they were selected to be included in the review.

\section{RESULTS}

All the studies included in the review were divided into one of the four regions: Africa, Asia, Eastern Europe, and South America. Each of the four regions will be described separately.

\section{AFRICA}

\section{Countries covered}

A total of 16 articles covering the Africa region were included in this review in Ref. (4-19). The countries covered were: Ghana, Liberia, Nigeria, Sierra Leone, South Africa, and Uganda (4, 7-10, 13, 14, 16, 19). Publication dates ranged from 1972 to 2013 (7, $11,19)$. Six articles provided reviews and surveys on the continent as a whole and one article reported on developing countries in general $(5,6,11,12,15,17,18)$. Radiation capacity is not discussed for a majority of countries on the African continent. The two most recent articles present updated data for the African continent: Denny and Anorlu reviewed cervical cancer in Africa and the IAEA reported on the status of RT resources in Africa $(5,11)$.

\section{Cancers treated}

The most common cancer addressed was cervical cancer, though seven articles included data on non-gynecological cancers $(8,11$, $12,14,15,17,18)$. Advanced cervical cancer is treated with radiation, a combination of external beam radiation and brachytherapy. It is estimated that 80,000 African women are diagnosed with cervical cancer each year and approximately 60,000 die of the disease annually, though validation of these estimations is difficult due

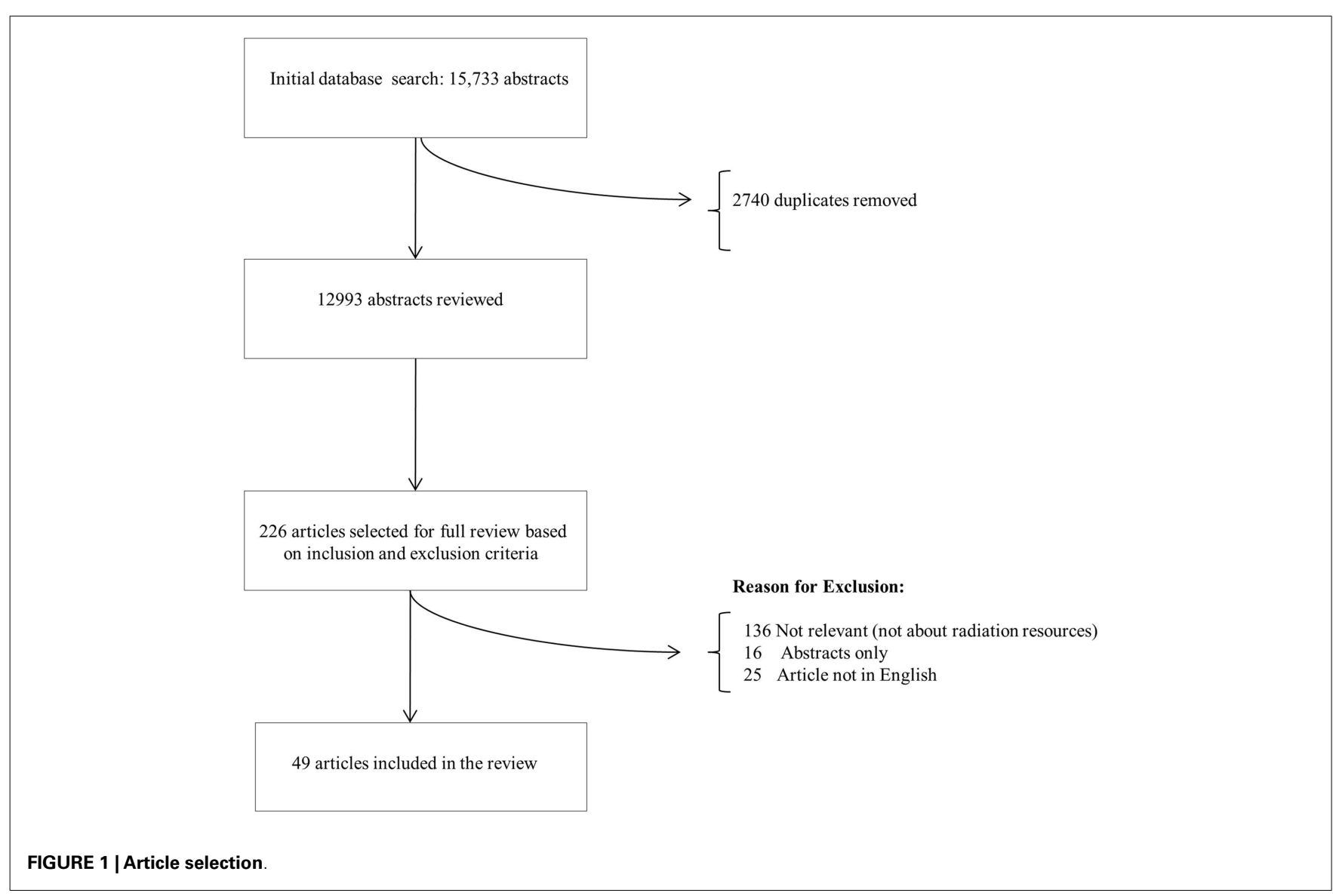


to limited availability of cancer registries (6). RT is frequently the first line of treatment for cervical cancer, and, in a single institution survey, up to $97.3 \%$ of newly diagnosed patients were referred for RT (13). However, the article did not describe where these centers are located and how many women were actually treated or able to access these centers. Unfortunately, many women do not present for follow-up at these tertiary care centers, which makes it challenging to evaluate outcomes. Radiation is also used for palliative treatment with notable improvement in survival (12). However, the 5-year cervical cancer survival rate continues to be low, ranging from 15 to $30 \%$ in Africa compared to $60 \%$ in North America (12).

\section{Available equipment}

According to the latest update from the DIRAC database, there are currently 160 RT centers on the African continent (11). A total of 88 cobalt- 60 machines, half of which are over 20 years old, and 189 linear accelerators are operating in those 160 centers. Sixty percent of machines are concentrated in Egypt and South Africa, while 29 of 54 countries in Africa are still lacking any RT resource. Given the ideal ratio of 4-8.1 RT centers per 1 million people or $1 \mathrm{MV}$ per 250,000 people, as defined by the IAEA, every country in Africa needs more centers and machines (17). The highest capacity is in Mauritius with 2.36 centers/ 1 million people followed by South Africa with 1.89, Tunisia with 1.55, and Egypt with 0.93 (17). Not surprisingly, there appears to be a correlation between Gross National Income (GNI) and RT capacity (11).

There are limited reports from most of West Africa with the exception of Nigeria. Several reports on Nigeria from as early as 1972 record a gradual increase in RT delivery capacity over time. In 1972, the longest standing RT center had been in existence for 20 years, housing one linear accelerator and two sets of brachytherapy applicators (7). Between 1972 and 1990, reports from West Africa suggested that there were a total of two RT centers that served Ghana, Liberia, Nigeria, and Sierra Leone (8). During this time, cervical cancer patients were treated with brachytherapy alone. In 2000, the University College Hospital in Ibadan, Nigeria, reported a 500 case retrospective review where combined external beam RT and low dose rate brachytherapy was used to treat patients with cervical cancer, an improvement from previous reports where hospital resources allowed for only monotherapy with low dose rate brachytherapy $(4,7)$. In 2008, five RT centers were in operation in Nigeria, with more expected to come (10). Despite the gradual increase in RT centers, waiting lines for these machines continue to be long. Nigeria and the surrounding West African countries are clearly operating under capacity.

\section{Human resources}

Data on available RT human resources were limited with specific numbers only available for South Africa. In 1994, with a population of 24 million, South Africa had 58 practicing radiation oncologists, 190 therapy radiographers, and 30 medical physicists, which represented only a fraction of total registered professionals (14). With 58 radiation oncologists, South Africa had only 1 radiation oncologist per 350 patients, falling short of the recommended IAEA ratio of 1 radiation oncologist per 200-250 patients (20). In 2011, a review of cervical cancer treatment in Africa reported that "training facilities in cancer diagnosis and management" were few and only found in Algeria, Egypt, Libya, Morocco, Nigeria, South Africa, and Zimbabwe (6). It was unclear whether the curriculum covered RT or if the types of health care professionals trained (physicians vs. nurses vs. technicians) would be able to deliver RT after completion of the program. Multiple articles also emphasized the critical lack of pathology and laboratory services needed to make the initial diagnosis of gynecological and other cancers $(12,15)$. The articles from Nigeria provide limited records of their human resources. One mention is made of the RT center in 1972, where only one Cambridge-trained medical physicist was noted to be available to the entire hospital (7).

\section{AMERICAS}

\section{Countries covered}

A total of five full articles covering Central America, South America, and the Caribbean were included in this review in Ref. (2125). The countries covered were: Argentina, Bolivia, Brazil, Chile, Colombia, Costa Rica, Cuba, Dominican Republic, Ecuador, El Salvador, Guatemala, Haiti, Mexico, Nicaragua, Panama, Paraguay, Peru, Uruguay, and Venezuela. Four articles provided surveys of multiple South American countries, one article reported on Mexico alone, and one abstract reported on Brazil alone. No data were found for 20 of 26 countries in this region, including Belize, Grenada, Guyana, Honduras, Jamaica, and Suriname. The earliest article was published in 1984 and detailed RT resources throughout nine Latin American countries. The next most recent survey of Latin America was published in 2004 by the IAEA, and included 19 countries that account for $96 \%$ of the cancer cases in South and Central America and the Caribbean. The most recent article included in this review was published in 2013 and reported RT patterns in Mexico. Data from this region are sparse and available for limited time periods.

\section{Cancers treated}

The data on the most common cancers treated in this region were limited. In 1984, the report from nine Latin American countries found the most common cancer treated by radiation therapy to be cervical, followed by breast, head and neck, lung, and skin cancers (21). A 2013 report from Mexico suggested that the most common cancer treated by radiation therapy is breast cancer, followed by prostate, cervical, and lung (22).

\section{Available equipment}

The number of radiation machines in Latin America has increased over the past 30 years, especially in countries with greater populations. From 1989 to 2004, the number of machines in Brazil rose from 165 to 270 (64\% increase) and, in Venezuela, from 18 to $44(144 \%$ increase $)(21,23)$. The most recent information from 2004 lists the number of RT centers, cobalt-60 machines, and linear accelerators (linacs) from 19 Latin American countries (23). The total number of centers in the region was 470, with 710 machines, slightly more than half of which were cobalt-60 units (396 cobalt-60 units, 314 linacs). However, the distribution of these centers varied widely from country to country, ranging from 0 to 151. Although there has been a steady increase in the number of machines, the capacity remains insufficient, with an estimated 100 
more teletherapy machines required to meet the IAEA guidelines of 1 machine per 500 new cancer cases per year (23). The quality of the machines and downtime was not discussed in more recent papers. In 1990, the majority of linacs in these countries were older machines operating at 4-10 MV without electron capability (24). Though the numbers of teletherapy machines in these countries are on the rise, it is unclear whether these have reliable power sources (for linear accelerators) and access to adequate servicing. Similar to Africa, there continues to be an insufficient number of machines to serve the populations in these countries.

Brachytherapy was offered at the majority of centers in Latin America, but the numbers of centers varied throughout the region. In 1990, all centers in Peru and Chile had brachytherapy for treatment of gynecologic malignancies, and $90 \%$ of centers in Brazil offered manual afterloading (24). Of 12 countries that provided data on brachytherapy, there were over 260 sets of cesium and radium manual afterloading devices, 23 cesium low dose rate afterloading devices, and 6 cesium high dose rate afterloading devices. However, the break down by country was not provided. In addition, there were 103 centers with iridium high dose rate units, 61 of which were in Brazil (23).

\section{Human resources}

In addition to an insufficient number of radiation therapy centers, there continues to be inadequate numbers of personnel trained to provide treatment. In 1983, of 27 radiation therapy centers studied in nine Latin American countries, 35.5\% had an insufficient number of full-time radiation oncologists ( $<1$ per 200-250 patients), $52 \%$ had an insufficient number of full-time physicists $(<1$ per 400 new patients), and only 15 of the centers had a dosimetrist available (21). However, they found that 25 of the 27 centers had an adequate number of radiation technicians (21). In 2004, the 19 countries studied had 933 radiation oncologists, with 642 more needed, representing a needed increase of $69 \%$ in number of radiation oncologists to meet IAEA standards (23). There were 357 medical physicists with 627 new physicists needed representing a $146 \%$ needed increase. There were 2300 radiation technologists, with 2500 more technologists needed (23). At the time of publication, only Bolivia and Venezuela had $>1$ radiation oncologist per 1000 cancer cases (23).

Formal training programs for radiation oncology are on the rise. In 1989, 10 out of 27 centers surveyed had radiation oncology residency programs and 14 offered formal training for radiation therapy technologists (21). By 2004, 12 of the 18 countries surveyed had postgraduate radiation oncology training at a total of 35 institutions, with the highest density of training in Argentina, Brazil, and Cuba (23). As of 2013, there are six centers in Mexico that were training radiation oncologists (22). Formal training of medical physicists is available in 7 of 18 Latin American countries at 22 centers (23). In Mexico specifically, two public universities offer a Masters in Medical Physics (22). However, the quality of these institutions and training programs was not described.

\section{ASIA}

\section{Countries covered}

A total of 20 full articles covering the Asia region were included in this review in Ref. (26-45). Of the countries, the United Nations
Statistics Division classified as belonging to Asia, this systematic review covers the following LMIC: Azerbeijan, Bangladesh, Cambodia, China, India, Indonesia, Malaysia, Myanmar, Philippines, Saudi Arabia, Sri Lanka, Thailand, Turkey, and Vietnam. Nepal and Papau New Guinea were not included in the UN classification, but were included in the Asia region for the purposes of this review in Ref. (46). No data were found on Armenia, Bhutan, Georgia, Islamic Republic of Iran, Jordan, Kazakhstan, Kyrzygstan, People's Democratic Republic of Lao, Tajikstan, Uzbekistan, or Yemen. The earliest article was written about Bangladesh in 1981 and the most recent article was written about India in 2013 $(26,45)$.

\section{Cancers treated}

Data on RT utilization were largely focused on treatment of cervical cancer (35-42). In the Philippines, $75.6 \%$ of new cervical cancer patients seen at Philippine General Hospital in 2008 were reportedly eligible for chemoradiation, yet financial constraints resulted in only $17.6 \%$ completing the recommended treatment course (39). In Indonesia, a total of 10,274 patients received RT in 2007. Eight centers were actively performing brachytherapy. In Indonesia, intracavitary insertions for cervical cancer represented the most common brachytherapy procedure (33). In Cambodia, a 2012 report noted 60 patients per day were treated with RT, but did not describe the distribution of cancer sites treated (31).

\section{Available equipment}

The most recent published survey of RT machines across Asia and the Pacific region was from the IAEA in 2001 (30). They report the number of RT centers ranged from 1 to 453, cobalt-60 machines ranged from 2 to 381, and linear accelerators ranged from 0 to 286 in countries in Asia. The number of cobalt- 60 units far outweighed the number of accelerators, with the exception of Thailand and Malaysia, where the ratio of accelerators to cobalt-60 units was 1.08 and 2.71 , respectively.

Some of the articles included in this review published after the 2001 IAEA report provide more updated figures on machine availability. Eav et al. reported that the RT department in Phnom Penh, Cambodia, was refurbished in 2003 with a second-hand cobalt-60 unit, $\mathrm{x}$-ray simulator, and 2D dosimetry system, as well as a new remote afterloading brachytherapy machine (31). Two years earlier, when IAEA report was published, Cambodia did not have any reported equipment, reflecting the relatively rapid rate of change in the state of RT in Asia over the last decade. The plan for the new national cancer center in Cambodia includes two new linear accelerators and a high dose rate brachytherapy system.

In Turkey, as of 2011, there were 40 cobalt-60 units, 146 linear accelerators ( 1.8 linear accelerators per 1 million population), and 35 brachytherapy units (32). Large regional gaps were reported, however, with nearly $40 \%$ of linacs concentrated in two cities. As of 2008 in Indonesia, there were 22 RT centers, 17 cobalt- 60 units, and 18 linear accelerators, which represent a very large increase over the 7 years since the 2001 IAEA report (33). This rapid equipment scale-up was also seen in India, where 12 additional linear accelerators were added over a 4-year period from 2001 to 2005 (34). In 2005, there were also 113 operational brachytherapy facilities, of which 44 were high dose rate units. 


\section{Human resources}

Training of skilled personnel for RT was frequently cited as a major barrier to scaling up treatment delivery, despite a reported increase in human resource availability. In Cambodia, international partnerships between the University of Phnom Penh and other international centers, including Strasbourg University in France, has facilitated oncologist training (31). A 2-year program for general practitioners to obtain additional training in oncology has also been created, and, since 2011, a 5-year oncology specialization has been launched. There is currently one full professor oncologist in the country. In Indonesia, there was a 31\% increase in RT personnel from 2004 to 2008 and the country has undertaken an expansion of its residency program (33).

In Turkey, the number of radiation oncologists has risen from 85 in 1985 to 446 by 2011, with an average of 30 new radiation oncologists entering practice per year (32). With this trend, Turkey will be in line with international benchmarks by 2023 . There remains, however, a gap of 187-280 medical radiation physicists (representing a 10-65\% personnel increase) and 600-800 RT technicians (representing 100-133\% increase) in Turkey (32). To address these personnel gaps, additional university programs have been opened and working hours of existing staff have been extended.

\section{EASTERN EUROPE}

\section{Countries covered}

A total of two full articles covering the Eastern Europe region were included in this review. According to the United Nation Statistics Division and World Bank, the following countries are classified as LMIC in Eastern Europe: Belarus, Bulgaria, Hungary, Republic of Moldova, Romania, and Ukraine (47). The articles included covered the following four countries: Bulgaria, Hungary, Moldova, and Romania. No data were found on Belarus or the Ukraine. Both articles were international reviews; the updated results from the Patterns of Care for Brachytherapy in Europe (PCBE) was written in 2010 and the analysis of the European DIRAC database was written in $2013(48,49)$.

\section{Cancers treated}

The only available data on the most commonly treated cancers were found pertaining to brachytherapy in the PCBE study (48). Eastern European LMIC included in the analysis was classified in group II (Hungary) or group III (Bulgaria, Moldova, and Romania). In both group II and III, endometrial carcinoma was the most common cancer treated using brachytherapy (38\% of cases in group II and $22 \%$ of cases in group III), followed by cervical cancer ( $31 \%$ of cases in group II and $57 \%$ of cases in group III). Both group II and group III treated more gynecological cancers with brachytherapy than group I, which consisted of high resource countries such as the United Kingdom, Germany, and France. This was attributed to higher incidence rates of uterine and cervical cancer in group II and III countries compared to group I.

\section{Available equipment}

The most updated information on the numbers of RT centers, cobalt-60 units, and linear accelerator machines were derived from the DIRAC database as follows: Bulgaria (13 centers, 10 cobalt-60 units, 5 linacs), Hungary ( 13 centers, 11 cobalt-60 units, 27 linacs), and Romania (19 centers, 16 cobalt, 12 linacs) (49). In Eastern Europe, cobalt-60 machines represent the majority of teletherapy machines, with linear accelerators accounting for only $31 \%$ of all teletherapy machines in countries like Bulgaria, Hungary, and Romania. The number of MV teletherapy machines per million people ranged from 1.3 in Romania to 3.8 in Hungary.

\section{Human resources}

No data were available on radiation oncology healthcare provider training programs.

\section{DEVELOPING WORLD}

Seven articles non-specific to a particular world region presented analyses of the cancer burden, resources, and demographic and economic trends affecting disease control in the developing world (50-56). Increased GNI and population size were found to be critical factors in the availability of radiation resources, with higher rates of equipment acquisition and an increased density of RT services in large and high-income countries (50). Experts observe that while knowledge, technology, and infrastructure to transport the technology are available, the lack of funding prevents scientific societies and international organization from transferring these resources to countries in need (51). The literature suggests that for developing countries, any plan to improve access to RT would need to be dynamic and multi-faceted, requiring buy-in at the levels of the local and state government, investment in staff training that is consistent across countries, increased physical capital and infrastructure, and improvement in patient cancer education programs $(52,53)$.

\section{GAPS IN RADIATION FACILITIES AND GAPS IN PUBLISHED LITERATURE}

To further characterize gaps in radiation facilities, we constructed a table comparing country-specific needs in radiation oncology infrastructure and the current state of available resources per the DIRAC database (Table 1) $(57,58)$. As seen in Table 1, except for a few LMIC, most countries are significantly lacking in their radiation infrastructure.

Most of the recent literature in this review was derived from international databases; few articles were generated from within individual countries or regions reporting original, institutionspecific, and up-to-date numbers. To highlight gaps in published literature, we compared the non-DIRAC-derived systematic review literature to the most recent DIRAC country-specific statistics (Table 2) (57). Only 11 countries out of the 47 included in this review had non-DIRAC-related publications. We extracted facility and equipment numbers based on non-DIRAC sources and found that most estimates were outdated and only Indonesia, Mexico, and Turkey had recent publications reflecting their current RT capacity. This demonstrates significant gap in published literature focusing on state of radiation oncology facilities in LMIC.

\section{DISCUSSION}

In this report, we present the results of a comprehensive systematic review of the literature on RT capacity in LMIC. Compared to IAEA recommendations, our review found an overwhelming lack of radiation oncology capacity relative to the large cancer burden faced by these populations (20). While the situation 
Table 1 | Comparison of estimated radiotherapy machines needed taking into account cancer incidence rates vs. the reported machine counts in the DIRAC database.

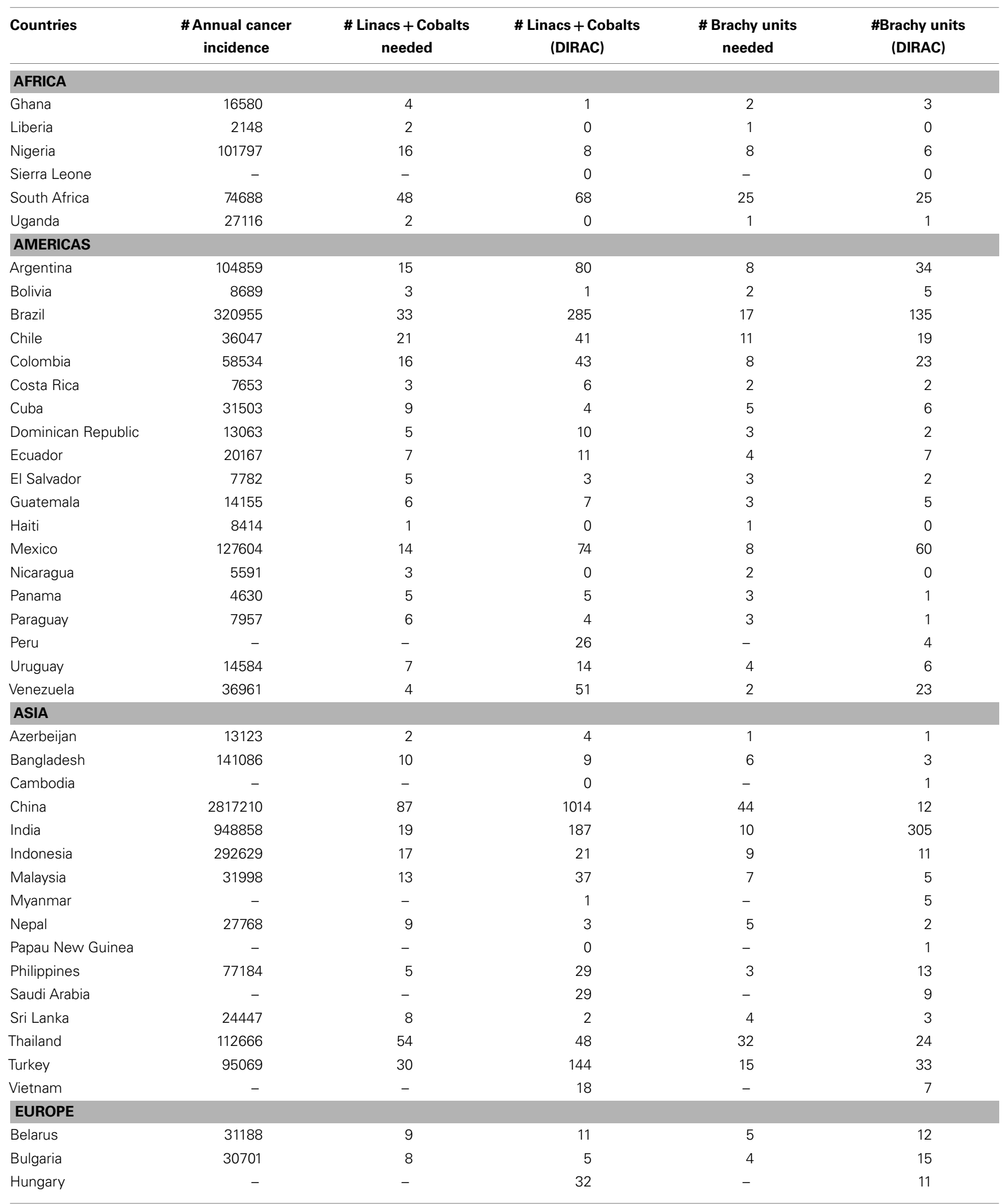


Table 1 | Continued

\begin{tabular}{lccccc}
\hline Countries & $\begin{array}{c}\text { \# Annual cancer } \\
\text { incidence }\end{array}$ & $\begin{array}{c}\text { \# Linacs + Cobalts } \\
\text { needed }\end{array}$ & $\begin{array}{c}\text { \# Linacs + Cobalts } \\
\text { (DIRAC) }\end{array}$ & $\begin{array}{c}\text { \# Brachy units } \\
\text { needed }\end{array}$ & $\begin{array}{c}\text { \#Brachy units } \\
\text { (DIRAC) }\end{array}$ \\
\hline Republic of Moldova & 9395 & 3 & 1 & 2 & 2 \\
Romania & 70262 & 8 & 19 & 4 & 6 \\
Ukraine & 142960 & 15 & 21 & 8 & 50 \\
\hline
\end{tabular}

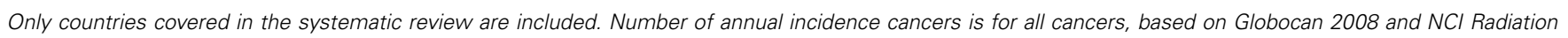

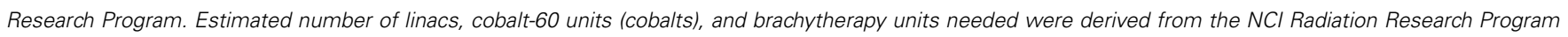

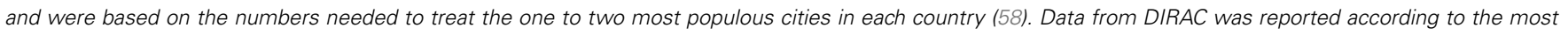
updated web database (57). DIRAC, Directory of Radiotherapy Centres. "-" symbol indicates no information available.

varies across regions and countries, many major challenges were similar. The most significant challenges reported include the quality and quantity of physical resources, the scarceness of human resources, and the unequal distribution of available resources. A recently published IAEA/DIRAC report reemphasized several of these issues (59).

Across regions, the number, age, and quality of machines contribute to suboptimal RT capacity. Many countries rely on machines that are more than 20 years old, which brings their functionality and reliability to question $(11,17)$. Because RT is first-line treatment for the vast majority of cervical cancers, many women with cervical cancer simply do not receive any treatment at all given the paucity of available RT centers. For example, in the Philippines, less than $20 \%$ of eligible women successfully receive radiation for their cancer (40). This is reflected in abysmally low 5 -year survival rates for cervical cancer (15-30\% in Africa) compared to higher income countries (60\% in North America) (5, 6). While the numbers of centers providing radiation therapy in Latin American countries may be on the rise, the majority of these centers do not have simulation $(81 \%)$ or treatment planning systems (55\%) (23). The high upfront investment required at the local, state, and national government levels makes improving the quality and quantity of physical resources particularly challenging.

The lack of adequate human resources is another factor contributing to poor RT capacity in developing countries. Most reports on radiation oncology personnel availability and training indicate that there are not enough physicians and staff to treat the numbers of patients requiring radiation treatment. High patient volumes and lack of trained personnel often lead to long waiting lines and continued disease progression long after diagnosis. In Africa, there was only one report on radiation oncology personnel, which was specific to South Africa and reported that there were not enough radiation oncologists to meet the population's needs (14). Although there are no published articles regarding human resources in other African countries, the situation is most likely similar, or more serious, than that of South Africa. In the Americas, the most recent survey of the region's capacity reported the major constraint to adequate provision of radiation therapy was an insufficient number of specialists, rather than a lack of equipment (23). The inadequate number of personnel is in part due to an insufficient number of training programs for radiation oncologists, medical physicists, and radiation technologists. However, there has been a shift from a majority of radiation oncologists receiving training abroad to training locally; it is unclear what the impact of this will be on the numbers of providers of RT in these countries in the future (23). It is imperative that the availability of training in radiation oncology be improved to appropriately utilize existing physical resources, meet the maximum utilization potential, and account for attrition of workers over time.

The concentrated distribution of available radiation machines compounds the issue of limited capacity in many LMICs by restricting access to needed treatment. Generally, countries with higher GNI house the majority of radiation machines, with LMIC falling far short of the IAEA recommendations. Many countries do not have any radiation centers at all. For example, in Latin America, $75 \%$ of radiation oncology departments are located in the four most populous countries: Brazil, Mexico, Columbia, and Argentina (23). No published evidence suggests that Haiti has any regional access to radiation machines; however, neighboring Dominican Republic has three centers (23). It appears as if developed areas have a few large, high capacity centers, with the rest of the population having limited access to, at best, small, suboptimal centers (21). There is usually no mechanism in place for improving access for more rural populations and affordability of care remains a critical barrier (44).

Other culture, infrastructure, and systems issues contribute to poor capacity as well. In Africa, limited public knowledge and belief in traditional African healing contribute to more advanced disease at presentation, increasing requirements for palliative radiation and effective pain medication (4). While radiation can be very effective as palliative therapy, public information campaigns should go hand in hand with cancer prevention programs to urge women to seek medication attention earlier for better treatment outcomes (19). Another frequently highlighted issue was the difficulty in conducting a needs assessment for RT due to the lack of an organized cancer registry in many countries. Of the two articles about Eastern Europe, both were based on international registry and survey data. None originated internally within each country and therefore the RT capacity of this region remains limited to what is reported by DIRAC and IAEA.

Despite existing challenges, we discovered several countries working to improve their RT delivery systems. There are reports demonstrating slow and gradual increases in the number of RT centers in countries of West Africa (8). The number of Nigerian radiation centers and machines has been on the rise for over 30 years and is now also serving other countries of West Africa ( 7 , 
Table 2 | Comparison of radiotherapy resources described in reported literature vs. the DIRAC database (57).

\begin{tabular}{|c|c|c|c|c|c|c|c|c|c|c|}
\hline Countries & $\begin{array}{c}\text { \# RT } \\
\text { centers } \\
\text { (literature) }\end{array}$ & $\begin{array}{c}\text { \# RT } \\
\text { centers } \\
\text { (DIRAC) }\end{array}$ & $\begin{array}{c}\text { \# Linacs + } \\
\text { Cobalts } \\
\text { needed }\end{array}$ & $\begin{array}{l}\text { \# Linacs } \\
\text { (literature) }\end{array}$ & $\begin{array}{l}\text { \# Linacs } \\
\text { (DIRAC) }\end{array}$ & $\begin{array}{c}\text { \# Cobalt-60s } \\
\text { (literature) }\end{array}$ & $\begin{array}{l}\text { \# Cobalt-60s } \\
\text { (DIRAC) }\end{array}$ & $\begin{array}{c}\text { \# Brachy } \\
\text { units } \\
\text { needed }\end{array}$ & $\begin{array}{l}\text { \# Brachy } \\
\text { units } \\
\text { (literature) }\end{array}$ & $\begin{array}{c}\text { \# Brachy } \\
\text { units } \\
\text { (DIRAC) }\end{array}$ \\
\hline Ghana (8) & 0 & 3 & 4 & - & 1 & - & 3 & 2 & - & 3 \\
\hline Liberia (8) & 0 & 0 & 2 & 0 & 0 & 0 & 0 & 1 & 0 & 0 \\
\hline Nigeria $(5,6)$ & 5 & 9 & 16 & - & 8 & - & 5 & 8 & - & 6 \\
\hline South Africa (14) & $>13$ & 39 & 48 & 20 & 68 & 19 & 11 & 25 & $>5$ & 25 \\
\hline Uganda & - & 1 & 2 & - & 0 & - & 1 & 1 & - & 1 \\
\hline \multicolumn{11}{|l|}{ AMERICAS } \\
\hline Argentina (24) & - & 82 & 15 & 12 & 80 & 80 & 36 & 8 & - & 34 \\
\hline Bolivia & - & 5 & 3 & - & 1 & - & 5 & 2 & - & 5 \\
\hline Cuba & - & 9 & 9 & - & 4 & - & 10 & 5 & - & 6 \\
\hline Dominican Republic & - & 9 & 5 & - & 10 & - & 3 & 3 & - & 2 \\
\hline Ecuador & - & 10 & 7 & - & 11 & - & 6 & 4 & - & 7 \\
\hline El Salvador & - & 4 & 5 & - & 3 & - & 3 & 3 & - & 2 \\
\hline Guatemala & - & 8 & 6 & - & 7 & - & 3 & 3 & - & 5 \\
\hline Haiti & - & 0 & 1 & - & 0 & - & 0 & 1 & - & 0 \\
\hline Mexico (22) & 83 & 91 & 14 & - & 74 & - & 61 & 8 & - & 60 \\
\hline Nicaragua & - & 1 & 3 & - & 0 & - & 2 & 2 & - & 0 \\
\hline Panama & - & 2 & 5 & - & 5 & - & 0 & 3 & - & 1 \\
\hline Paraguay & - & 3 & 6 & - & 4 & - & 1 & 3 & - & 1 \\
\hline China (28) & - & 1050 & 87 & 62 & 1014 & 186 & 516 & 44 & - & 12 \\
\hline India $(27,34)$ & 129 & 314 & 19 & 47 & 187 & 184 & 333 & 10 & 113 & 305 \\
\hline Indonesia (33) & 22 & 23 & 17 & 18 & 21 & 17 & 19 & 9 & - & 11 \\
\hline Malaysia & - & 25 & 13 & - & 37 & - & 6 & 7 & - & 5 \\
\hline Myanmar & - & 4 & - & - & 1 & - & 7 & - & - & 5 \\
\hline Nepal (35) & - & 5 & 9 & - & 3 & - & 3 & 5 & 1 & 2 \\
\hline Papau New Guinea & - & 1 & - & - & 0 & - & 2 & - & - & 1 \\
\hline Philippines & - & 34 & 5 & - & 29 & - & 10 & 3 & - & 13 \\
\hline Saudi Arabia & - & 12 & - & - & 29 & - & 1 & - & - & 9 \\
\hline Sri Lanka & - & 7 & 8 & - & 2 & - & 11 & 4 & - & 3 \\
\hline Thailand & - & 29 & 54 & - & 48 & - & 28 & 32 & - & 24 \\
\hline Turkey (32) & 90 & 95 & 30 & 146 & 144 & 40 & 59 & 15 & 35 & 33 \\
\hline Vietnam (43) & 9 & 19 & - & 3 & 18 & 13 & 19 & - & 12 & 7 \\
\hline \multicolumn{11}{|l|}{ EUROPE } \\
\hline Belarus & - & 12 & 9 & - & 11 & - & 21 & 5 & - & 12 \\
\hline Bulgaria & - & 13 & 8 & - & 5 & - & 10 & 4 & - & 15 \\
\hline Hungary & - & 13 & - & - & 32 & - & 11 & - & - & 11 \\
\hline
\end{tabular}


Table 2 | Continued

\begin{tabular}{|c|c|c|c|c|c|c|c|c|c|c|}
\hline Countries & $\begin{array}{c}\text { \# RT } \\
\text { centers } \\
\text { (literature) }\end{array}$ & $\begin{array}{c}\text { \# RT } \\
\text { centers } \\
\text { (DIRAC) }\end{array}$ & $\begin{array}{c}\text { \# Linacs + } \\
\text { Cobalts } \\
\text { needed }\end{array}$ & $\begin{array}{c}\text { \# Linacs } \\
\text { (literature) }\end{array}$ & $\begin{array}{l}\text { \# Linacs } \\
\text { (DIRAC) }\end{array}$ & $\begin{array}{c}\text { \# Cobalt-60s } \\
\text { (literature) }\end{array}$ & $\begin{array}{c}\text { \# Cobalt-60s } \\
\text { (DIRAC) }\end{array}$ & $\begin{array}{c}\text { \# Brachy } \\
\text { units } \\
\text { needed }\end{array}$ & $\begin{array}{c}\text { \# Brachy } \\
\text { units } \\
\text { (literature) }\end{array}$ & $\begin{array}{c}\text { \# Brachy } \\
\text { units } \\
\text { (DIRAC) }\end{array}$ \\
\hline Republic of Moldova & - & 1 & 3 & - & 1 & - & 3 & 2 & - & 2 \\
\hline Romania & - & 22 & 8 & - & 19 & - & 15 & 4 & - & 6 \\
\hline Ukraine & - & 56 & 15 & - & 21 & - & 89 & 8 & - & 50 \\
\hline
\end{tabular}

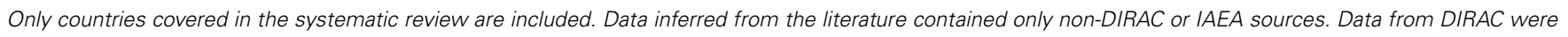

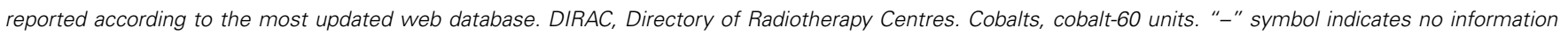
available.

$8,10)$. Recently, there have been substantial increases in teletherapy machines in Latin American countries, such as Brazil and Venezuela, and several countries now have 1-4 MV per million population. Brachytherapy is also available in the majority of Latin American countries with other RT capacity $(23,24)$. The data also suggest rapid changes in available technology, which reflects the economic development and modernization in the region. From 1976 to 1999, there was a threefold increase in megavolt teletherapy machines in Southeast Asian countries (30). More recently, there has been an increase of approximately 25 machines per year in India alone (44). Although there has not been a full survey of the region's RT resources since 2001, available data suggest that these trends are continuing in many countries. In 2004, Vietnam initiated a "National Program on Cancer Prevention." Included in this program was a target of one oncology department per province, each one equipped with RT machines (43). There is some evidence that capacity is slowly improving with increased volume of machines and improved radiation oncology training programs, especially in Indonesia and Cambodia $(31,33)$. Cambodia's University of Phnom Penh successfully partnered with international centers and universities to provide training for oncologists (31). There also have been efforts from National Cancer Institute Center of Global Health, IAEA, Union for International Cancer Control (UICC), and academic centers in the United States to help narrow the gap in RT access and training. Many of these collaborations are still developing and require persistent effort from institutions in the US and other developing countries to make these collaborations productive and successful (60-63). African organization on Research and Training in Cancer (AORTIC) has also been leading several efforts in improving cancer care capacity in Africa (64).

Comparing the numbers of RT centers and machines enumerated by the literature in the systematic review to DIRAC, we found the literature to be out of date. Of all non-DIRAC reports included in the review, only 14 unique articles provided updated numbers for a total of 11 countries. With the exception of Indonesia, Mexico, and Turkey, most were written prior to 2008 and were no longer accurate. Many of these countries may have their own national cancer registries and databases for RT resources, but they do not appear to be publishing on this data. This may suggest that established international databases, such as DIRAC, may be sufficient and comprehensive enough to serve as the primary sources for global radiation equipment inventory. National registries may then be used for other purposes such as directing resources toward regions that need machine maintenance and replacement or informing decisions on where to develop new RT resources.

The primary strength of this study is the robustness of the search strategy. The thoroughness of the search terms and wide scope of sources searched ensured that very few reports were missed. However, despite the robustness of the search, the review is mainly limited by data availability. While it is likely that the lack of information is directly correlated to a lack of RT services, it is also possible that institutions lack incentives to report on RT services given DIRAC's international presence and historically regular reporting. Furthermore, it is important to note that treatment of cancer requires capacity in a variety of areas in addition to RT such as radiology, surgery, medical oncology, and pathology. Therefore, this review presents a small but significant aspect of the cancer care continuum. We acknowledge that delineating the challenges of radiation capacity does not capture the entire picture of access and delivery of cancer treatment.

\section{CONCLUSION}

Though many LMIC struggle to meet the demand for radiation therapy delivery, few reports exist in the literature about these issues. This systematic review identifies major challenges to delivering RT in these regions, including lack of physical resources, lack of human personnel, and lack of data. DIRAC reports and online resources likely reflect real-time changes in RT capacity, but non-DIRAC-originated reports tend to be out of date, even in countries with national cancer registries. Institutions should publish more data on their capacity to deliver RT and the specific challenges they face; only then can interventions aimed at mitigating these issues be developed. Where possible, neighboring countries should collaborate and share resources to improve the scope of RT delivery, particularly when there is an economic disparity between neighboring countries. Furthermore, international funding agencies should make increasing RT capacity in LMIC a priority.

\section{ACKNOWLEDGMENTS}

Dr. Ana Isabel Tergas is the recipient of a fellowship (NCI R25 CA094061-11) from the National Cancer Institute.

\section{SUPPLEMENTARY MATERIAL}

The Supplementary Material for this article can be found online at http://www.frontiersin.org/Journal/10.3389/fonc.2014. 00380/abstract 


\section{REFERENCES}

1. Kanavos P. The rising burden of cancer in the developing world. Ann Oncol (2006) 17(Suppl 8):viii15-23. doi:10.1093/annonc/mdl983

2. Farmer P, Frenk J, Knaul FM, Shulman LN, Alleyne G, Armstrong L, et al. Expansion of cancer care and control in countries of low and middle income: a call to action. Lancet (2010) 376(9747):1186-93. doi:10.1016/S0140-6736(10) 61152-X

3. Levin V, Tatsuzaki H, Meghzifene A, Izewska J. Improving cancer care. Increased need for radiotherapy in developing countries. IAEA Bull 2001 43(2):25-32.

4. Campbell OB, Arowojolu AO, Akinlade BI, Adenipekun A, Babarinsa IA. Advanced cervical carcinoma in Ibadan, Nigeria: an appraisal of radiation therapy. J Obstet Gynecol (2000) 20(6):624-7. doi:10.1080/01443610020001503

5. Denny L, Anorlu R. Cervical cancer in Africa. Cancer Epidemiol Biomarkers Prev (2012) 21(9):1434-8. doi:10.1158/1055-9965.EPI-12-0334

6. Denny L. Cervical cancer treatment in Africa. Curr Opin Oncol (2011) 23(5):469-74. doi:10.1097/CCO.0b013e3283495a3f

7. Duncan JT. Medical application of radiation in Nigeria. J Natl Med Assoc (1972) 64(4):366-9.

8. Durosinmi-Etti F. An overview of cancer management by radiotherapy in Anglophone West Africa. Int J Radiat Oncol Biol Phys (1990) 19(5):1263-6. doi:10.1016/0360-3016(90)90240-K

9. Jennings OG, Soeters RP, Tiltman AJ, van Wijk AL, Dehaeck K, Bloch B, et al. The natural history of carcinoma of the cervix in young women. $S$ Afr Med J (1992) 82:351-4.

10. Airede L, Onakewhor J, Aziken M, Ande A, Aligbe J. Carcinoma of the uterine cervix in Nigerian women: the need to adopt a national prevention strategy. Sahel Med J (2008) 11(1):1-11. doi:10.4314/smj2.v11i1.12957

11. Abdel-Wahab M, Bourque J, Pynda Y, Izewska J, Van der Merwe D, Zubizarreta E, et al. Status of radiotherapy resources in Africa: an international atomic energy agency analysis. Lancet Oncol (2013) 14(4):e168-75. doi:10.1016/S14702045(12)70532-6

12. Adewuyi SA, Ajekigbe AT, Campbell OB, Mbibu NH, Oguntayo AO, Kolawole $\mathrm{AO}$, et al. Pattern of oncologic emergencies seen in adult cancer patients attending the radiotherapy and oncology centre, Ahmadu Bello University Teaching Hospital, Zaria - Nigeria. Niger Postgrad Med J (2012) 19(4):208-14.

13. Ikechebelu J, Onyiaorah I, Ugboaja J, Anyiam D, Eleje G. Clinicopathological analysis of cervical cancer seen in a tertiary health facility in Nnewi, south-east Nigeria. J Obstet Gynaecol (2010) 30(3):299-301. doi:10.3109/ 01443610903531394

14. Levin CV, Sitas F, Odes RA. Radiation therapy services in South Africa. S Afr Med J (1994) 84(6):349-51.

15. Martin WMC. Radiotherapy in developing countries. Br J Radiol (1993) 66(782):220-4.

16. Wabinga H, Ramanakumar A, Banura C, Luwaga A, Nambooze S, Parkin D. Survival of cervix cancer patients in Kampala, Uganda: 1995-1997. Br J Cancer (2003) 89(1):65-9. doi:10.1038/sj.bjc.6601034

17. Levin CV, El Gueddari B, Meghzifene A. Radiation therapy in Africa: distribution and equipment. Radiother Oncol (1999) 52(1):79-83. doi:10.1016/S01678140(99)00069-9

18. Thomas J. Cancer control in Africa: a call for action. Afr J Med Med Sci (2004) 33(1):1-4.

19. Ago BU, Agan TU, Ekanem EI. Cancer of the uterine cervix at the University of Calabar Teaching Hospital, Calabar Nigeria. Cancer Res J (2013) 1(4):37-40. doi:10.11648/j.crj.20130104.12

20. Slotman BJ, Cottier B, Bentzen SM, Heeren G, Lievens Y, van den Bogaert W. Overview of national guidelines for infrastructure and staffing of radiotherapy. ESTRO-QUARTS: work package 1. Radiother Oncol (2005) 75(3):349-54. doi:10.1016/j.radonc.2004.12.005

21. Souhami L. Quality assurance in radiation therapy: clinical aspects. Int J Radiat Oncol Biol Phys (1984) 10:69-72. doi:10.1016/0360-3016(84)90451-6

22. Poitevin-Chacón A, Hinojosa-Gómez J. Patterns of care of radiotherapy in México. Rep Pract Oncol Radiother (2013) 18(2):57-60. doi:10.1016/j.rpor.2012. 09.001

23. Zubizarreta EH, Poitevin A, Levin CV. Overview of radiotherapy resources in Latin America: a survey by the International Atomic Energy Agency (IAEA). Radiother Oncol (2004) 73(1):97-100. doi:10.1016/j.radonc.2004.07.022

24. Calmon Teixeira L. Situation of radiotherapy in Latin America. Int J Radiat Oncol Biol Phys (1990) 19(5):1267-70. doi:10.1016/0360-3016(90)90241-B
25. Candelaria M, Cetina L, Garcia-Arias A, Lopez-Graniel C, de la Garza J, Robles E, et al. Radiation-sparing managements for cervical cancer: a developing countries perspective. World J Surg Oncol (2006) 4:77. doi:10.1186/1477-78194-77

26. Lynch HT, Rahim MA. Cancer in the third world: Bangladesh 1980. Am J Public Health (1981) 71(10):1158-61. doi:10.2105/AJPH.71.10.1158

27. Dinshaw K. Radiation oncology: the Indian scenario. Int J Radiat Oncol Biol Phys (1996) 36(4):941-3. doi:10.1016/S0360-3016(96)00386-0

28. Fu LT. Radiotherapy in China today. Int J Radiat Oncol Biol Phys (1989) 16(2):293-5. doi:10.1016/0360-3016(89)90316-7

29. Martin WC. Radiotherapy and oncology in Papua New Guinea - how it differs from western practice. Australas Radiol (1990) 34(3):238-40. doi:10.1111/ j.1440-1673.1990.tb02639.x

30. Tatsuzaki H, Levin CV. Quantitative status of resources for radiation therapy in Asia and Pacific region. Radiother Oncol (2001) 60(1):81-9. doi:10.1016/S01678140(01)00330-9

31. Eav S, Schraub S, Dufour P, Taisant D, Ra C, Bunda P. Oncology in Cambodia. Oncology (2012) 82(5):269-74. doi:10.1159/000336791

32. Goksel F, Koc O, Ozgul N, Gultekin M, Abacioglu M, Tuncer M, et al. Radiation oncology facilities in Turkey: current status and future perspectives. Asian Pac J Cancer Prev (2011) 12(9):2157-62.

33. Gondhowiardjo S, Prajogi G, Sekarutami S. History and growth of radiation oncology in Indonesia. Biomed Imaging Interv J (2008) 4(3):e42. doi:10.2349/ biij.4.3.e42

34. Biswas LN, Deb AR, Pal S. Radiation therapy: experience in Indian patients. J Indian Med Assoc (2005) 103(9):486-8.

35. Prasiko G, Jha A, Dong J, Srivastava R. Experience of brachytherapy in carcinoma of uterine cervix at BP Koirala Memorial Cancer Hospital, Bharatpur, Chitwan, Nepal. J Nepal Med Assoc (2004) 43(151):19-22.

36. Malik S, Banu PA, Rukhsana N, Ahmed M, Yasmin Z. A comprehensive study on HDR brachytherapy treatments of cervical cancers: using the first Co-60 BEBIG Multisource Unit in Bangladesh. J Contemp Brachytherpy (2011) 3(2):96-105. doi:10.5114/jcb.2011.23205

37. Mahantshetty U, Krishnatry R, Kumar S, Engineer R, Maheshwari A, Kerkar R, et al. Consensus meeting and update on existing guidelines for management of cervical cancer with special emphasis on the practice in developing countries, including India: the expert panel at the 8 th annual women's cancer initiative Tata Memorial Hospital Conference 2010-11. Indian J Med Paediatr Oncol (2012) 33(4):216. doi:10.4103/0971-5851.107083

38. Lertbutsayanukul C, Lertsanguansinchai P, Shotelersuk K, Khorprasert C, Rojpornpradit $\mathrm{P}$, Asavametha $\mathrm{N}$, et al. Results of radiation therapy in stage $1 \mathrm{~B}$ cervical carcinoma at King Chulalongkorn Memorial Hospital: fifteen-year experience. J Med Assoc Thai (2001) 84(Suppl 1):S216-27.

39. Liu S, Huang X, Ke G, Huang X. 3D radiation therapy or intensity-modulated radiotherapy for recurrent and metastatic cervical cancer: the Shanghai Cancer Hospital experience. PLoS One (2012) 7(6):e40299. doi:10.1371/journal.pone. 0040299

40. Domingo EJ, Dy Echo AV. Epidemiology, prevention and treatment of cervical cancer in the Philippines. J Gynecol Oncol (2009) 20(1):11-6. doi:10.3802/jgo. 2009.20.1.11

41. Manusirivithaya S, Sripramote M, Tangjitgamol S, Sanjareonsuttikul N, Pisarnturakit P. Cost effectiveness of concurrent chemoradiation in comparison with radiation alone in locally advanced cervical cancer. J Med Assoc Thai (2005) 88(8):1035-44.

42. Ma J, Zhu Q, Han S, Zhang Y, Ou W, Wang H, et al. Effect of socio-economic factors on delayed access to health care among Chinese cervical cancer patients with late rectal complications after radiotherapy. Gynecol Oncol (2012) 124(3):395-8. doi:10.1016/j.ygyno.2011.11.040

43. To DA, Bui D. Current status of radiotherapy in Vietnam, 2002. Radiat Med (2004) 22(1):12-6.

44. Ravichandran R. Has the time come for doing away with cobalt-60 teletherapy for cancer treatments. J Med Phys (2009) 34(2):63-5. doi:10.4103/0971-6203. 51931

45. Chandel SS, Singh KK, Nigam AK, Baghel RS. "The effect of treatment prolongation in treatment of cervical cancer patient" - treated patients at rural center in India. IOSR-JDMS (2013) 9(2):70-5. doi:10.9790/0853-0927075

46. National Classifications. (2014). Available from: http://unstats.un.org/unsd/cr/ ctryreg/ctrylist 2 .asp? $\mathrm{rg}=6$ 
47. United Nations Statistics Division. United Nations Statistics Division - Standard Country and Area Codes Classifications (M49). (2014). Available from: http://unstats.un.org/unsd/methods/m49/m49regin.htm\#europe

48. Guedea F, Venselaar J, Hoskin P, Hellebust TP, Peiffert D, Londres B, et al. Patterns of care for brachytherapy in Europe: updated results. Radiother Oncol (2010) 97(3):514-20. doi:10.1016/j.radonc.2010.09.009

49. Rosenblatt E, Izewska J, Anacak Y, Pynda Y, Scalliet P, Boniol M, et al. Radiotherapy capacity in European countries: an analysis of the Directory of Radiotherapy Centres (DIRAC) database. Lancet Oncol (2013) 14(2):e79-86. doi:10.1016/S1470-2045(12)70556-9

50. Levin V, Tatsuzaki H. Radiotherapy services in countries in transition: gross national income per capita as a significant factor. Radiother Oncol (2002) 63(2):147-50. doi:10.1016/S0167-8140(02)00010-5

51. Hanson G, Stjernswärd J, Nofal M, Durosinmi-Etti F. An overview of the situation in radiotherapy with emphasis on the developing countries. Int J Radiat Oncol Biol Phys (1990) 19(5):1257-61. doi:10.1016/0360-3016(90)90239-G

52. Barton MB, Frommer M, Shafiq J. Role of radiotherapy in cancer control in low-income and middle-income countries. Lancet Oncol (2006) 7(7):584-95. doi:10.1016/S1470-2045(06)70759-8

53. Zaidi H. Medical physics in developing countries: looking for a better world. Biomed Imaging Interv J (2008) 4:1-5. doi:10.2349/biij.4.1.e29

54. Ansink AC. Cervical cancer in developing countries: how can we reduce the burden? Awareness raising, screening, treatment and palliation. Trop Doct (2007) 37(2):67-70. doi:10.1258/004947507780609284

55. Kitchener HC, Hoskins W, Small W Jr, Thomas GM, Trimble EL, Cervical Cancer Consensus Group. The development of priority cervical cancer trials: a Gynecologic Cancer InterGroup report. Int J Gynecol Cancer (2010) 20(6):1092-100. doi:10.1111/IGC.0b013e3181e730aa

56. Martin W. Cancer in developing countries: part I - cancer burden, resources, epidemiology, aetiology and clinical practice. Clin Oncol (1998) 10(4):219-25. doi:10.1016/S0936-6555(98)80004-6

57. Division for Human Health: DIRAC (DIrectory of RAdiotherapy Centres). (2014). Available from: http://nucleus.iaea.org/HHW/DBStatistics/DIRAC/index.html

58. National Cancer Institute Radiation Research Program. Human Resources Needed for Cancer Control in Low \& Middle Income Countries. (2014). Available from: http://rrp.cancer.gov/programsResources/human_resources_needed.htm

59. Datta NR, Samiei M, Bodis S. Radiation therapy infrastructure and human resources in low-and middle-income countries: present status and projections for 2020. Int J Radiat Oncol Biol Phys (2014) 89(3):448-57. doi:10.1016/j.ijrobp. 2014.03.002
60. Fisher BJ, Daugherty LC, Einck JP, Suneja G, Shah MM, Dad LK, et al. Radiation Oncology in Africa: improving access to cancer care on the African continent. Int J Radiat Oncol Biol Phys (2014) 89(3):458-61. doi:10.1016/j.ijrobp. 2013.12.032

61. Jaffray DA, Gospodarowicz M. Bringing global access to radiation therapy: time for a change in approach. Int J Radiat Oncol Biol Phys (2014) 89(3):446-7. doi:10.1016/j.ijrobp.2014.05.019

62. Einck JP, Hudson A, Shulman AC, Yashar CM, Dieng MM, Diagne M, et al. Implementation of a high-dose-rate brachytherapy program for carcinoma of the cervix in senegal: a pragmatic model for the developing world. Int J Radiat Oncol Biol Phys (2014) 89(3):462-7. doi:10.1016/j.ijrobp.2013.12.008

63. Bvochara-Nsingo M, Grover S, Gierga DP, Makufa R, Efstathiou JA, Dixit N, et al. Cervical brachytherapy exchange: steps toward oncology capacity building in Botswana. Oncologist (2014) 19(7):e1-2. doi:10.1634/theoncologist.2014MA- 1

64. Williams CK, Stefan DC, Rawlinson F, Simbiri K, Mbulaiteye SM. The African Organisation for Research and Training in Cancer and its conferences: a historical perspective and highlights of the Ninth International Conference, Durban, South Africa, 21-24 November 2013. Ecancermedicalscience (2014) 8:396. doi:10.3332/ecancer.2014.396

Conflict of Interest Statement: The authors declare that the research was conducted in the absence of any commercial or financial relationships that could be construed as a potential conflict of interest.

Received: 18 November 2014; accepted: 18 December 2014; published online: 22 January 2015.

Citation: Grover S, Xu MJ, Yeager A, Rosman L, Groen RS, Chackungal S, Rodin D, Mangaali M, Nurkic S, Fernandes A, Lin LL, Thomas G and Tergas AI (2015) A systematic review of radiotherapy capacity in low- and middle-income countries. Front. Oncol. 4:380. doi: 10.3389/fonc.2014.00380

This article was submitted to Radiation Oncology, a section of the journal Frontiers in Oncology.

Copyright $\odot 2015$ Grover, Xu, Yeager, Rosman, Groen, Chackungal, Rodin, Mangaali, Nurkic, Fernandes, Lin, Thomas and Tergas. This is an open-access article distributed under the terms of the Creative Commons Attribution License (CC BY). The use, distribution or reproduction in other forums is permitted, provided the original author(s) or licensor are credited and that the original publication in this journal is cited, in accordance with accepted academic practice. No use, distribution or reproduction is permitted which does not comply with these terms. 